\title{
Thyroid hormones and seasonal reproductive neuroendocrine interactions
}

\author{
Nobuhiro Nakao ${ }^{1}$, Hiroko Ono ${ }^{1}$ and Takashi Yoshimura ${ }^{1,2,3}$ \\ ${ }^{1}$ Division of Biomodeling, Laboratory of Animal Functional Genomics, ${ }^{2}$ Graduate School of Bioagricultural Sciences, \\ Avian Bioscience Research Center and ${ }^{3}$ Institute for Advanced Research, Nagoya University, Furo-cho, Chikusa-ku, \\ Nagoya 464-8601, Japan \\ Correspondence should be addressed to T Yoshimura; Email: takashiy@agr.nagoya-u.ac.jp
}

\begin{abstract}
Many animals that breed seasonally measure the day length (photoperiod) and use these measurements as predictive information to prepare themselves for annual breeding. For several decades, thyroid hormones have been known to be involved in this biological process; however, their precise roles remain unknown. Recent molecular analyses have revealed that local thyroid hormone activation in the hypothalamus plays a critical role in the regulation of the neuroendocrine axis involved in seasonal reproduction in both birds and mammals. Furthermore, functional genomics analyses have revealed a novel function of the hormone thyrotropin. This hormone plays a key role in signaling day-length changes to the brain and thus triggers seasonal breeding. This review aims to summarize the currently available knowledge on the interactions between elements of the thyroid hormone axis and the neuroendocrine system involved in seasonal reproduction.
\end{abstract}

Reproduction (2008) 136 1-8

\section{Photoperiodism}

Many animals inhabiting regions in the temperature zone limit their reproductive activity to specific seasons in order to maximize the survival of their offsprings. Species that have a short incubation or gestation period, such as birds and small mammals, produce young during spring and summer; therefore, they are known as longday breeders. By contrast, species that have a gestation period of about 5 or 6 months, such as sheep, goats, and deer, enter breeding in the autumn; therefore, they are known as short-day breeders. These seasonal breeding animals use the changes occurring in the day length (photoperiod) as a calendar and accordingly regulate many of their physiological and behavioral processes, including reproduction, migration, molting, hibernation, and body weight alterations. In long-day breeders, the increase in the photoperiod during spring stimulates the secretion of the gonadotropin-releasing hormone $(\mathrm{GnRH})$ from the hypothalamus and the subsequent release of gonadotropins (luteinizing hormone (LH) and follicle-stimulating hormone $(\mathrm{FSH})$ ) from the pituitary gland. By contrast, the decrease in the photoperiod during autumn stimulates the secretion of these hormones in short-day breeders. This phenomenon is termed as 'photoperiodism'. Prolactin secretion is also known to be photoperiodically regulated (reviewed by Morgan \& Williams 1996). However, its release is not driven by thyroid hormones (Dahl et al. 1994). Furthermore, previous studies have revealed that the blockade of seasonal reproductive functions due to lesions or hypothalamo-pituitary disconnection does not affect the seasonal secretion of prolactin (Juss 1993, Lincoln 2002). Therefore, we do not focus on prolactin in the present review.

\section{Melatonin and seasonality}

In all vertebrates, melatonin is secreted on a daily basis by the pineal gland under the control of the circadian system; its secretion peaks during the subjective night and ceases during the day. The duration of melatonin secretion tracks night length and in mammal this humoral signal is considered a crucial component of the mechanism governing mammalian photoperiodism (Reiter 1993, Goldman 2001). In mammals, light signals are received by the eye and are then transmitted to the circadian pacemaker in the hypothalamus, i.e., the suprachiasmatic nucleus (SCN). The $\mathrm{SCN}$ drives the nocturnal rhythm of melatonin secretion by the pineal gland, and a lesion in the SCN abolishes the circadian rhythms that govern the production and secretion of this hormone (Scott et al. 1995, Tessonneaud et al. 1995). Hamsters and sheep have been shown to develop photoperiodic blindness following pinealectomy (Hoffman \& Reiter 1965, Bittman et al. 1983). In addition, 
melatonin secretion for a long duration (i.e., short-day pattern) suppresses gonadotropin secretion in hamsters (Bartness et al. 1993) but stimulates it in sheep (Bittman \& Karsch 1984). Melatonin is considered to act on its membrane-bound receptors that are involved in the regulation of a various seasonal responses. Specific melatonin-binding sites have been identified by using ${ }^{125}$ I-labeled melatonin, and a study wherein lesions were created in melatonin-binding sites revealed that the mediobasal hypothalamus $(\mathrm{MBH})$ is essential for the melatonin-mediated photoperiodic control of reproduction in hamsters (Maywood et al. 1996). It has also been reported that microimplants of melatonin introduced into the $\mathrm{MBH}$ of sheep regulate seasonal reproduction; this suggests that the $\mathrm{MBH}$ plays an important role in the photoperiodic mechanisms that operate in mammals (Lincoln 1992, Lincoln \& Maeda 1992, Malpaux et al. 1993). Although melatonin plays a critical role in the photoperiodic mechanisms as mentioned above, the downstream pathway involved in its functioning remains unknown.

Birds, just like mammals, secrete a daily rhythm of melatonin that tracks night length but, surprisingly, melatonin is not involved in the photoneuroendocrine axis regulating gonadotropin secretion and seasonal breeding (Kumar et al. 1993). Light is detected directly within the brain of birds via deep brain photoreceptors, and eyes are not required for this process. Despite the marked differences that exist between the mammalian and avian light input pathways for the regulation of photoperiodism, the $\mathrm{MBH}$ is considered the center for photoperiodic time measurement in both mammals and birds. This is because lesions in the $\mathrm{MBH}$ block photoinduced LH release (Sharp \& Follett 1969, Davies \& Follett 1975) even though the GnRH neurons are left intact (Juss 1993) and deep brain photoreceptors are thought to be localized in this region (Silver et al. 1988, Saldanha et al. 1994). In addition, circadian clock genes are expressed in the $\mathrm{MBH}$, and the circadian clock they regulate appears to be the long-sought biological clock responsible for photoperiodic time measurement (Ball \& Balthazart 2003, Yasuo et al. 2003).

\section{Thyroid hormones and seasonality}

For many decades, it has been known that interference with the thyroid glands (or exogenous treatment with thyroid hormones) has a wide range of effects upon seasonal reproduction in birds (recently summarized by Dawson \& Thapliyal 2001). Two major sets of effects have been described. First, exogenous treatment with thyroid hormones has been shown to mimic the effects of long-day conditions. Additionally, thyroid gland removal stops the development of photorefractoriness (i.e., insensitivity to previous stimulatory day-length) in birds and if carried out during the refractory period leads to its spontaneous dissipation (Follett \& Nicholls 1988,
Goldsmith \& Nicholls 1992, Wilson \& Reinert 1995, Bentley et al. 1997). Most of the molecular analyses described below have focused upon the involvement of thyroid hormones in long-day induced gonadotropin secretion and it is still unclear exactly how the thyroid is involved in refractoriness (refer to Dawson 1993, Dawson et al. 2001).

Fascinatingly, studies have shown that the thyroids are also involved in mammalian seasonal responses. In sheep, thyroidectomy stops the development of refractoriness in ewes (Nicholls et al. 1988) and rams (Parkinson \& Follett 1994, 1995). Work from Michigan and New Zealand groups suggests that then thyroid hormones are probably involved in the alterations in the responsiveness of the $\mathrm{GnRH}$ axis to the negative feedback effects of estrogen during the transition to anestrus (Moenter et al. 1991, Anderson et al. 2002). Although possible homologies between the avian and mammalian photoperiodic systems have been discussed, the precise role played by thyroid hormones in the regulation of seasonal reproduction has remained unclear for many decades.

\section{The Japanese quail - an excellent model for studying photoperiodism}

Although the mouse is a superb vertebrate model for many physiological processes, this is not true for seasonality and so work has focused upon species showing far stronger photoperiodic responses (quail, starlings, and white-crowned sparrows; sheep and hamsters). The Japanese quail (Coturnix japonica) offers some advantages when studying real-time photoperiodic changes. Quail respond to a single long day. Put briefly, photoperiodic induction occurs when light coincides with one particular phase of a circadian based rhythm of photoinducibility (Follett \& Sharp 1969). In quail, the most sensitive phase of this rhythm begins about $11 \mathrm{~h}$ after dawn and runs until about $1600 \mathrm{~h}$. If light occurs during this period (as in a long day) then a wave of gonadotropin secretion is triggered. The first detectable changes in $\mathrm{LH}, \mathrm{FSH}$, and $\mathrm{GnRH}$ secretion begin at about $2200 \mathrm{~h}$ of the first long day and a wave of secretion builds up over the next few days (Follett et al. 1977, Nicholls et al. 1983).

\section{Molecular analysis of photoperiodic time measurement}

We offered the hypothesis that in quail given light pulses during the photoinducible phase there would be molecular events induced within the $\mathrm{MBH}$ where the center for photoperiodic time measurement is localized. Based on this assumption, a differential subtractive hybridization analysis was performed by using the $\mathrm{MBH}$ of a quail that received light pulse and no light 

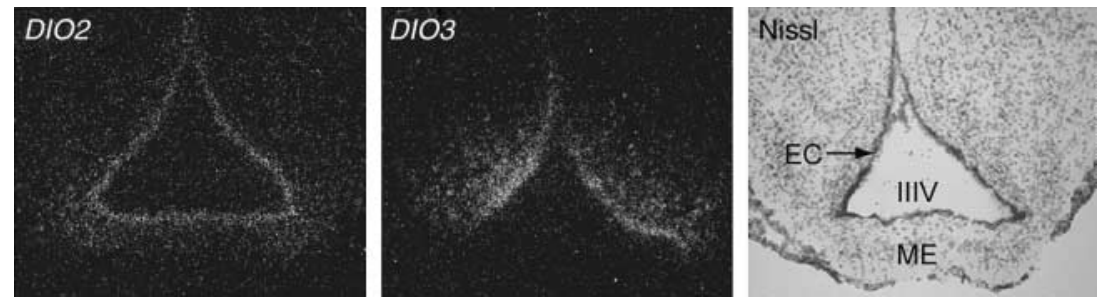

Figure 1 Expression of DIO2 and DIO3 in the MBH. Dark-field photomicrographs of the DIO2 and DIO3 expressions and a light-field photomicrograph of the Nissl-stained sections are shown. The images of DIO2 and DIO3 expressions were obtained from continuous long- and short-day stimulated birds respectively. EC, ependymal cell layer lining the ventrolateral walls of the third ventricle; ME, median eminence; and IIIV, third ventricle.

pulse at the photoinducible phase. From the analysis emerged one key gene encoding type 2 iodothyronine deiodinase (DIO2; D2) (Yoshimura et al. 2003). Acute induction of DIO2 expression by light was observed in the dorsal $\mathrm{MBH}$, around the paraventricular organ. Furthermore, upregulation of DIO2 was observed in the ependymal cells lining the ventrolateral walls of the third ventricle and the infundibular nucleus (which is anatomically homologous to the mammalian arcuate nucleus) by the continuous long-day stimulus (Fig. 1). These observed photoinduced expression sites of DIO2 were in agreement with the results of lesion studies performed by Sharp \& Follett (1969). This suggests that DIO2 expression in both regions is potentially important for the induction of photoperiodic responses in the gonads (Yoshimura et al. 2003).

\section{Local activation of thyroid hormone is the key for the photoperiodic response}

A further discovery was that the expression of type 3 iodothyronine deiodinase (DIO3) was downregulated under long-day conditions at the same time as DIO2 was upregulated (Yasuo et al. 2005). The timing of the inverse changes was precise and began at about 16-18 $\mathrm{h}$ on the first long day to which the quail were exposed. This was some $4 \mathrm{~h}$ prior to first detectable rise in $\mathrm{LH}$ secretion. A strong argument that the DIO2/DIO3 changes were related to photoinduction came from finding that the gene changes lasted for a number of days after quail had been exposed to just one long photoperiod, just as occurred in the case of $\mathrm{LH}$ secretion. The enzyme DIO2 (D2) catalyzes the removal of an outer ring iodine from the prohormone thyroxine $\left(\mathrm{T}_{4}\right)$ and thus converts it into the bioactive form, i.e., 3, $3^{\prime}, 5$-tri-iodothyronine $\left(T_{3}\right)$. By contrast, the enzyme DIO3 (D3) catalyzes the removal of an inner ring iodine from $T_{4}$ and $T_{3}$ and thus converts them into reverse $T_{3}\left(r T_{3}\right)$ and $T_{2}$ respectively (Fig. 2; Leonard \& Visser 1986). Thus, both these enzymes play essential roles in the local control of the $T_{3}$ levels via mechanisms that operate under a various conditions to maintain the $T_{3}$ concentrations within a narrow range (Bernal 2002). Overall, it appeared as if the DIO2/DIO3 changes had the capacity to produce locally high concentrations of the $T_{3}$, the active thyroid hormone. Support for this idea came from finding that the $T_{3}$ concentrations in the $\mathrm{MBH}$ of the quail were found to be approximately ten times higher under long- than shortday conditions, while these concentrations in the plasma and other parts of the brain, such as the optic tectum and cerebellum, did not differ with the exposure conditions (Yoshimura et al. 2003).

Next, to validate the physiological significance of this local activation of the thyroid hormone, the effects of i.c.v. infusion of $\mathrm{T}_{3}, \mathrm{~T}_{4}$, and a DIO2 inhibitor were investigated. Although the effects of $\mathrm{T}_{4}$ infusion on testicular growth were minimal, $T_{3}$ administration under short-day conditions mimicked the effects of long-day conditions on testicular growth. In addition, i.c.v. infusion of a DIO2 inhibitor, namely iopanoic acid, impaired testicular growth under long-day conditions (Yoshimura et al. 2003). These results clearly indicated that the local activation of the thyroid hormone within the $\mathrm{MBH}$, induced by long-day conditions, plays a key role in the regulation of seasonal reproduction.

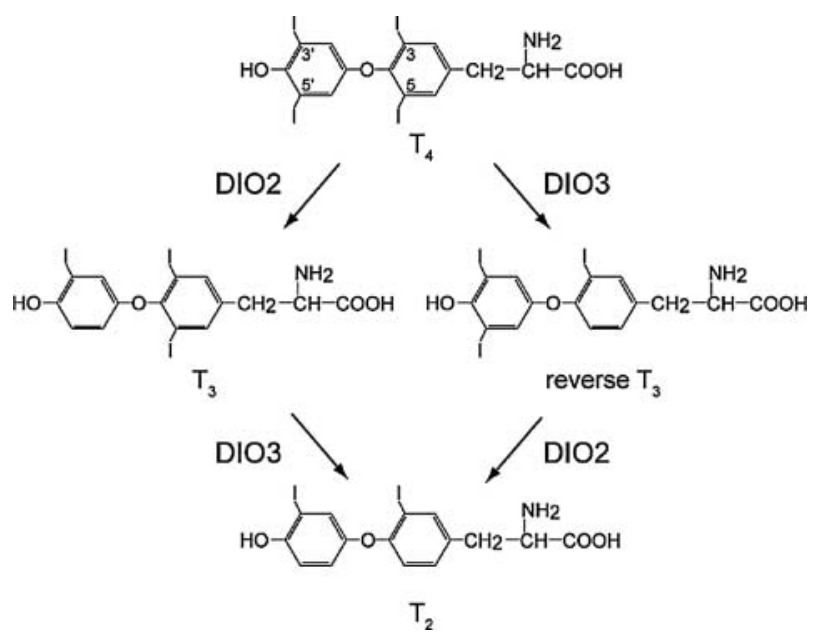

Figure 2 Structures and interrelationships between the principal iodothyronines in activated or inactivated form. Type 2 deiodinase (DIO2) generates active $T_{3}$ from $T_{4}$ by outer ring deiodination, whereas type 3 deiodinase (DIO3) catalyzes the conversion of both $\mathrm{T}_{3}$ and $\mathrm{T}_{4}$ to inactive form by inner ring deiodination. 


\section{Extension of findings to photoperiodic mammals}

At this point, a number of studies were undertaken by both ourselves and others that indicated that the DIO2/DIO3 discoveries may also apply in a number of photoperiodic mammals. Although some interspecies differences exist with regard to the relative importance of $\mathrm{DIO} 2$ and $\mathrm{DIO} 3$ in photoperiodism, the photoperiodic regulation of $\mathrm{DIO} 2$ and/or $\mathrm{DIO} 3$ expression has been confirmed in various mammalian species, including the Djungarian (Siberian) hamster (Watanabe et al. 2004, 2007, Barrett et al. 2007, Freeman et al. 2007), Syrian hamster (Revel et al. 2006, Yasuo et al. 2007a), rat (Yasuo et al. 2007 b), and goat (Yasuo et al. 2006). Further, $\mathrm{T}_{3}$ administered exogenously under short-day conditions was observed to mimic the effects of long-day conditions on gonadal growth in hamsters (Barrett et al. 2007, Freeman et al. 2007). In addition, it has been reported that the expressions of $\mathrm{DIO} 2$ and $\mathrm{DIO} 3$ are regulated by melatonin in mammals (Watanabe et al. 2004, Revel et al. 2006, Barrett et al. 2007, Yasuo et al. 2007a). It is also noteworthy that in goats, which breed under short-day conditions, a long-day stimulus suppressed the expression of DIO2; this effect was contrary to that observed in species that breed under longday conditions (Yasuo et al. 2006). In the ewe, the function of the thyroid hormone in suppressing seasonal activity is known to be limited to a specific seasonal window (Thrun et al. 1997, Billings et al. 2002), and the long-day suppression of DIO2 expression may provide a mechanism that accounts for the lack of responsiveness to $\mathrm{T}_{4}$ during the mid to late anestrus (Yasuo et al. 2006).

\section{Thyroid hormone uptake in the $\mathrm{MBH}$}

For a long time, it was believed that the thyroid hormone traverses the plasma membrane via passive diffusion due to its lipophilic nature. However, recent studies have revealed the existence of thyroid hormone transporters. Prendergast et al. (2002) reported that the expression patterns of thyroid hormone transporters such as transthyretin, $\mathrm{T}_{4}$-binding globulin, and albumin in Siberian hamsters differ following exposure to shortand long-day conditions. These transporters may be involved in the regulation of seasonal breeding in mammalian species. However, genes encoding these transporters were not observed to be expressed in the $\mathrm{MBH}$ of quail. On the contrary, in quail, organic anion transporting polypeptide 1c1 (OATP1C1) has been demonstrated to transport $\mathrm{T}_{4}$ from the cerebrospinal fluid (CSF) in the third ventricle to the ependymal cells lining the ventrolateral walls of the third ventricle, where DIO2 and DIO3 are expressed (Nakao et al. 2006). This indicates that OATP1C1 may play a role in the cellular uptake of $\mathrm{T}_{4}$ from the CSF to ependymal cells. Following this uptake, $\mathrm{T}_{4}$ is intracellularly converted either into active $\mathrm{T}_{3}$ due to the high DIO2 expression induced by long-day conditions or into inactive $\mathrm{rT}_{3}$ due to the high $\mathrm{DIO} 3$ expression induced by short-day conditions.

\section{Downstream events of thyroid hormone action}

Thyroid hormone exerts its effects via its nuclear receptors. In quail, weak mRNA expression of the thyroid hormone receptors $\alpha(T H R A)$ and $\beta(T H R B)$ and strong mRNA expression of the retinoid $X$ receptor $\alpha$ $(R X R A)$ have been observed in the basal tuberal hypothalamus $(\mathrm{BTH})$, which includes the median eminence and infundibular nucleus (Yoshimura et al. 2003); this indicates that the BTH is the target site for $T_{3}$ action. Thyroid hormones are known to be critically involved in the development, plasticity, and functioning of the central nervous system (CNS; Bernal 2002). Therefore, immunoelectron microscopy of the median eminence was performed for quail under both short- and long-day conditions. The nerve terminals of the $\mathrm{GnRH}$ neurons were observed to be in close proximity to the basal lamina under long-day conditions, while they were encased by the endfeet of the glial processes under shortday conditions (Yamamura et al. 2004). The administration of $\mathrm{T}_{3}$ into the brain brought about similar morphological changes and induced testicular growth under short-day conditions (Yamamura et al. 2006). In the glial cells of the median eminence, Fos-like immunoreactivity is induced by long-day stimulus, and this suggested that $\mathrm{GnRH}$ release may be controlled by the glial cells at the level of the nerve terminal (Meddle \& Follett 1997). Thus, morphological changes in the $\mathrm{GnRH}$ neurons and glial processes may regulate the seasonal secretion of $\mathrm{GnRH}$.

\section{A functional genomics analysis of photoperiodic induction in quail}

The chicken genomic sequence data, which have recently been made available, have permitted the expansion of studies on avian species from single-gene to genome-wide transcriptional analyses. To analyze the system dynamics and network structure in the $\mathrm{MBH}$ involved in regulating the photoperiodic activation of the thyroid hormone in the quail, which is a galliform bird closely related to the chicken, functional genomics analysis was performed using a chicken high-density oligonucleotide microarray (Affymetrix Chicken Genome Array) during the photoinduction process in quail exposed to an abrupt shift from short to long days (Nakao et al. 2008). The analysis (Fig. 3) identified two waves of gene expression. As found previously, there was upregulation of DIO2 and downregulation of DIO3, which began at about 1800-1900 h. This wave of gene change was accompanied by alterations in another nine genes including 


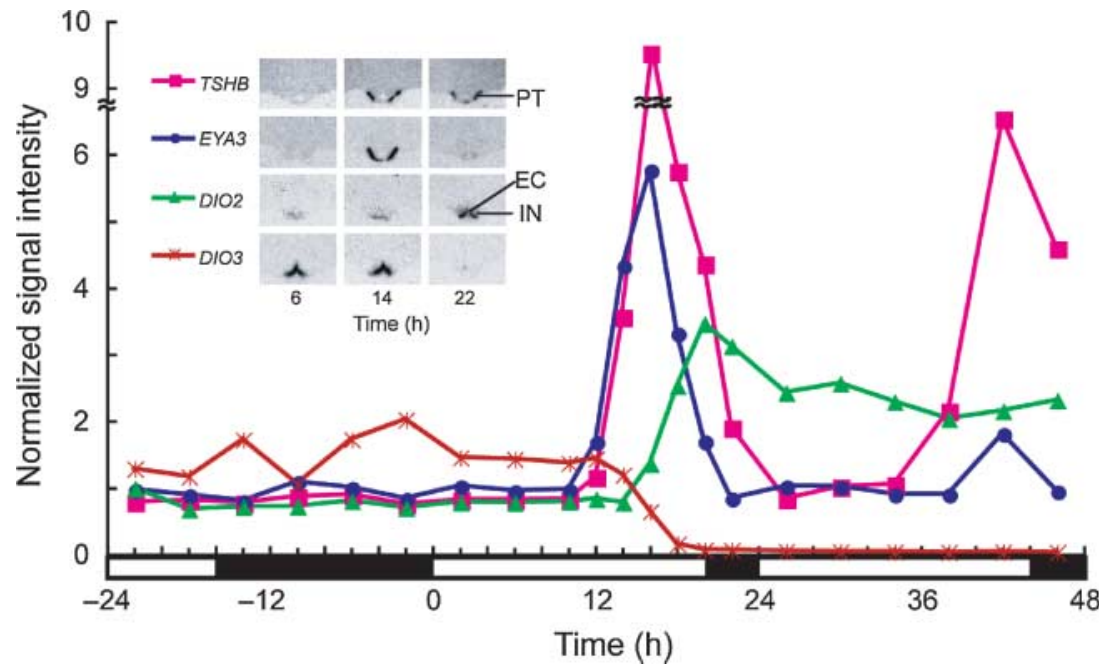

Figure 3 Identification of waves of gene expression during the photoinduction process. Induction of the first wave genes comprising the TSHB and EYA3 genes was followed by induction of the second wave genes, which included the DIO2 and $\mathrm{DIO} 3$ genes. Data were normalized such that the median signal strength for each gene over all time points was 1.0. The average signal strength at each point was then displayed as a ratio relative to the median signal strength of that gene. Expression of the first wave genes was observed in the pars tuberalis (PT), whereas that of the second wave genes was observed in the ependymal cell (EC) and the infundibular nucleus (IN). The time of $0 \mathrm{~h}$ corresponds to the dawn of the first long day.
ICER, NR4A3, and CEBPB. Of particular interest, however, was a wave of gene expression that began a few hours earlier at about $1400 \mathrm{~h}$ of the first long day. In particular two genes, thyroid-stimulating hormone $\beta(T S H B)$ and eyes absent 3 (EYA3), rose rapidly (Fig. 3) on the first long day and showed another wave of induction on day 2 . The timing of these two first wave genes is fascinating since it coincides with the phase of photoinducibility (Nicholls et al. 1983, Follett et al. 1998) while earlier experiments had indicated that by $1400 \mathrm{~h}$ a quail understands that it has been exposed to a long day even if $\mathrm{LH}$ secretion has not yet begun (Follett et al. 1977). A spatio-temporal expression analysis of the genes that produced the first and second expression waves revealed that these genes are localized in the pars tuberalis of the pituitary gland and in the ependymal cells lining the ventrolateral walls of the third ventricle in the $\mathrm{MBH}$ respectively. The pars tuberalis is a part of the adenohypophysis and is a highly vascularized multicellular tube of cells that surrounds the hypophyseal stalk (Stoeckel \& Porte 1984). Although EYA3 encodes a transcriptional coactivator, it seems unlikely that it regulates the expression of the second wave genes because its localization in the pars tuberalis is distinct from those of the second wave genes in the ependymal cells. On the other hand, TSHB encodes the $\beta$-subunit of TSH. Functional TSH requires two noncovalently linked subunits, a common pituitary glycoprotein $\alpha$-subunit (CGA) and TSH $\beta$. In addition to TSHB expression, CGA expression was observed in the pars tuberalis, and the photoinduction of TSH $\beta$-like immunoreactivity was confirmed in the pars tuberalis. The expression of TSH receptor $(T S H R)$ was observed in the ependymal cells lining the ventrolateral walls of the third ventricle, where the second wave genes are expressed, and the binding of ${ }^{125}$ I-labeled TSH was confirmed in this region. Since the median eminence is located outside the blood-brain barrier, it can be hypothesized based on our results that TSH induced in the pars tuberalis by long-day conditions acts on the TSHR localized on the ependymal cells in the $\mathrm{MBH}$, where the second wave genes are expressed.

\section{Pars tuberalis TSH triggers $\mathrm{DIO} 2$ expression}

The hypothesis that TSH triggers the expression of second wave genes was tested by i.c.v. injection of TSH and an anti-TSH $\beta$ antibody. TSH administration induced the expression of the second wave genes, including DIO2, in a dose-dependent manner, whereas the immunoneutralization of $\mathrm{TSH}$ by the administration of anti-TSH $\beta$ IgG impaired their expression that had been induced by long-day conditions. These results clearly indicated that $\mathrm{TSH}$ released in the pars tuberalis induces the expression of second wave genes. TSH is known to function via the TSHR-Gs $\alpha$-cAMP signaling pathway. When the promoter sequences of the second wave genes, including DIO2, ICER, NR4A3, and CEBPB, were determined in the quail and chicken, CAMP responsive elements were found to be highly conserved among these genes in both species. In addition, promoter analysis performed using the luciferase reporter revealed that $\mathrm{TSH}$ released in the pars tuberalis triggers the second wave gene expression via the TSHR-cAMP signaling pathway.

By subsequent microarray analysis, 183 genes were identified, whose expression patterns in the $\mathrm{MBH}$ differed between short- and long-day conditions. Among these genes, $T S H B$ and $C G A$ were observed to be markedly upregulated under long-day conditions. Therefore, the effects of chronic TSH administration on testicular growth were investigated. As expected, this TSH administration induced DIO2 expression and testicular growth. These results suggest that TSH released in the pars tuberalis under long-day conditions is important not only for the process of photoinduction but also for the maintenance of reproductive functions. 


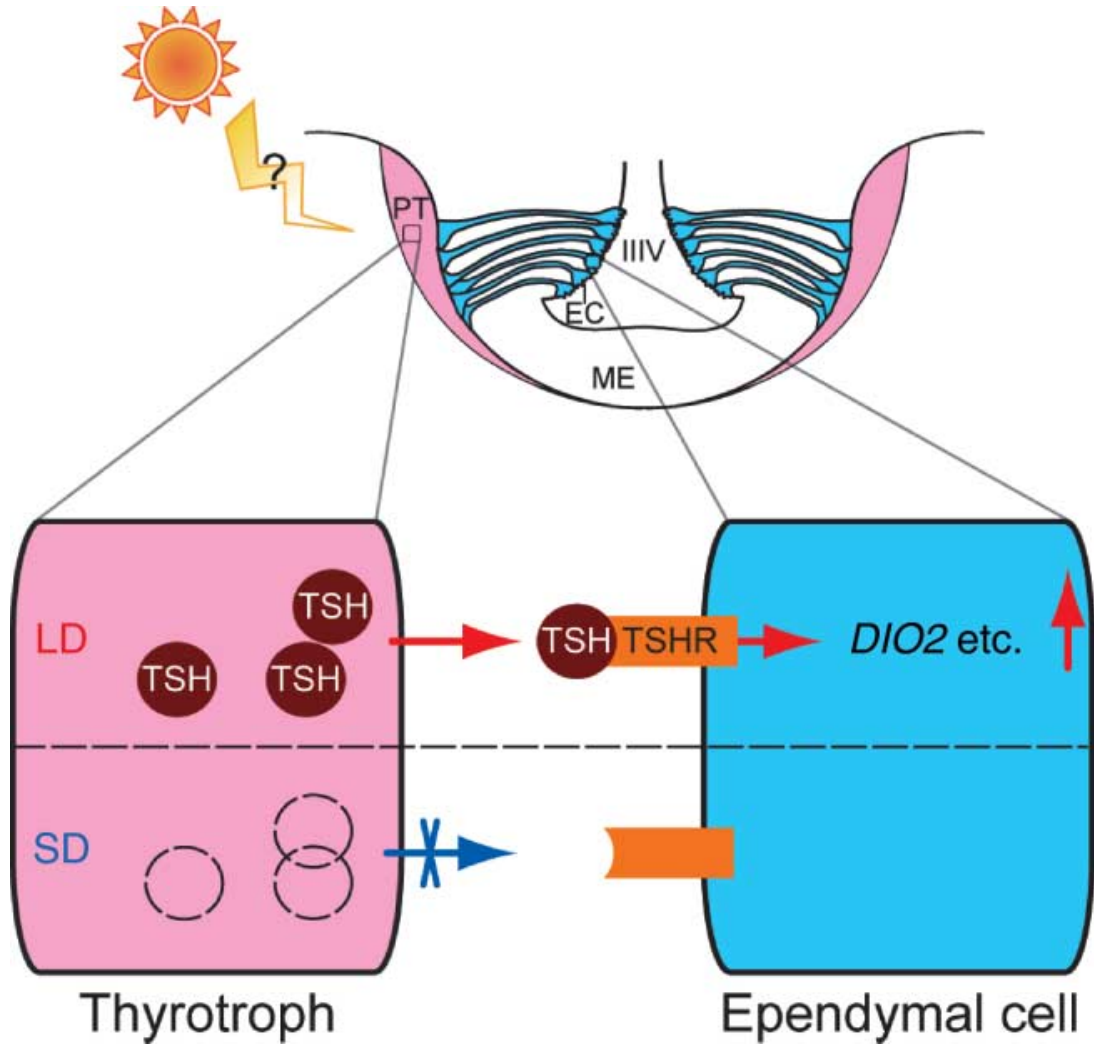

Figure $4 \mathrm{~A}$ model depicting a possible mechanism whereby thyroid hormones can regulate the photoperiodic response in birds. Light information received by the deep brain photoreceptors induces the expression of TSHB in the pars tuberalis (PT) of the pituitary gland. The light input pathway to the PT remains unknown. Long-day-induced TSH $\beta$ and cycling CGA (common pituitary glycoprotein $\alpha$-subunit) form TSH in the PT and act on the TSH receptor (TSHR) localized in EC. Expression of the second wave genes that include DIO2 is induced by TSH through the TSHR-cAMP signaling pathway.

\section{Conclusion}

Although the involvement of the thyroid hormone in the regulation of seasonal reproduction has long been recognized, its localization and the manner in which it exerts its function in this regard have remained unclear. Recent molecular analyses have revealed that local activation of the thyroid hormone by $\mathrm{DIO} 2$ and $\mathrm{DIO} 3$ in the $\mathrm{MBH}$ plays a critical role in the regulation of seasonal reproduction in both birds and mammals.

It has been reported that the expression of CGA and TSH $\beta$ in the mammalian pars tuberalis are photoperiodically regulated (Wittkowski et al. 1988, Bockmann et al. 1996, 1997). Furthermore, the expression of TSH has been detected in the CSF and CNS (Schaub et al. 1977, Hojvat et al. 1982) of mammals. In addition, TSHR has been reported to be expressed in the mammalian brain. The localization of melatonin receptors on the pars tuberalis suggests a photoperiodic function of the pars tuberalis in mammals (Morgan \& Williams 1996). However, the functional significance of TSH induction in the pars tuberalis with regard to the control of photoperiodic responses has remained unclear for many decades. Recent functional genomics analyses have demonstrated that TSH expression induced in the pars tuberalis by light stimuli triggers DIO2 expression in the MBH in birds (Fig. 4). These findings shed light on an entirely novel function of the pituitary hormone TSH and provide deeper insights into the functional significance of the pars tuberalis in birds. Future studies should aim to confirm whether TSH released in the pars tuberalis mediates the melatonin signal to DIO2/DIO3 expression in mammals. Further, the primary objective of immediate future research should be to identity the photoperiodic signaling pathway that activates the TSH in the avian pars tuberalis.

\section{Acknowledgements}

This work was supported in part by the Program for Promotion of Basic Research Activities for Innovative Biosciences (PROBRAIN), Grant-in-Aid for Scientific Research (B), and Grant-in-Aid for Young Scientists (S) from the JSPS to T Y. The authors declare that there is no conflict of interest that would prejudice the impartiality of this scientific work.

\section{References}

Anderson GM, Connors JM, Hardy SL, Valent M \& Goodman RL 2002 Thyroid hormones mediate steroid-independent seasonal changes in luteinizing hormone pulsatility in the ewe. Biology of Reproduction $\mathbf{6 6}$ 701-706

Ball GF \& Balthazart J 2003 Birds return every spring like clockwork, but where is the clock? Endocrinology 144 3739-3741.

Barrett P, Ebling FJP, Schuhler S, Wilson D, Ross AW, Warner A, Jethwa P, Boelen A, Visser TJ, Ozanne DM et al. 2007 Hypothalamic thyroid hormone catabolism acts as a gatekeeper for the seasonal control of body weight and reproduction. Endocrinology 148 3608-3617. 
Bartness TJ, Powers JB, Hastings MH, Bittman EL \& Goldman BD 1993 The timed infusion paradigm for melatonin delivery: what has it taught us about the melatonin signal, its reception, and the photoperiodic control of seasonal responses? Journal of Pineal Research 15 161-190.

Bentley GE, Goldsmith AR, Dawson A, Glennie LM, Talbot RT \& Sharp PJ 1997 Photorefractoriness in European starlings (Sturnus vulgaris) is not dependent upon the long-day-induced rise in plasma thyroxine. General and Comparative Endocrinology 107 428-438.

Bernal J 2002 Action of thyroid hormone in brain. Journal of Endocrinological Investigation 25 268-288.

Billings HJ, Viguie C, Karsch FJ, Goodman RL, Connors JM \& Anderson GM 2002 Temporal requirements of thyroid hormones for seasonal changes in LH secretion. Endocrinology 143 2618-2625.

Bittman EL \& Karsch FJ 1984 Nightly duration of pineal melatonin secretion determines the reproductive response to inhibitory day length in the ewe. Biology of Reproduction 30 585-593.

Bittman EL, Karsch FJ \& Hopkins JW 1983 Role of the pineal gland in ovine photoperiodism: regulation of seasonal breeding and negative feedback effects of estradiol upon luteinizing hormone secretion. Endocrinology 113 329-336.

Bockmann J, Böckers TM, Vennemann B, Niklowitz P, Müller J, Wittkowski W, Sabel B \& Kreutz MR 1996 Short photoperiod-dependent down-regulation of thyrotropin- $\alpha$ and $-\beta$ in hamster pars tuberalisspecific cells is prevented by pinealectomy. Endocrinology 137 1804-1813.

Bockmann J, Böckers TM, Winter C, Wittkowski W, Winterhoff $\mathbf{H}$, Deufel TH \& Kreutz MR 1997 Thyrotropin expression in hypophyseal pars tuberalis-specific cells is 3,5, $3^{\prime}$-triiodothyronine, thyrotropinreleasing hormone, and pit-1 independent. Endocrinology 138 1019-1028.

Dahl GE, Evans NP, Moenter SM \& Karsch FJ 1994 The thyroid gland is required for reproductive neuroendocrine responses to photoperiod in the ewe. Endocrinology 135 10-15.

Davies DT \& Follett BK 1975 The neuroendocrine control of gonadotrophin release in the Japanese quail. I. The role of the tuberal hypothalamus. Proceedings of the Royal Society of London, Series B: Biological Sciences 191 285-301.

Dawson A 1993 Thyroidectomy progressively renders the reproductive system of starlings (Sturnus vulgaris) unresponsive to changes in daylength. Journal of Endocrinology 139 51-55.

Dawson A \& Thapliyal JP 2001 The thyroid and photoperiodism. In Avian Endocrinology, pp 141-151. Eds A Dawson \& CM Chaturvedi. New Delhi: Narosa Publishing House.

Dawson A, King VM, Bentley GE \& Ball GF 2001 Photoperiodic control of seasonality in birds. Journal of Biological Rhythms 16 365-380.

Follett BK \& Nicholls TJ 1988 Acute effect of thyroid hormones in mimicking photoperiodically induced release of gonadotropins in Japanese quail. Journal of Comparative Physiology. B, Biochemical, Systemic, and Environmental Physiology 157 837-843.

Follett BK \& Sharp PJ 1969 Circadian rhythmicity in photoperiodically induced gonadotrophin release and gonadal growth in the quail. Nature 223 968-971.

Follett BK, Davies DT \& Gledhill B 1977 Photoperiodic control of reproduction in Japanese quail: changes in gonadotrophin secretion on the first day of induction and their pharmacological blockade. Journal of Endocrinology 74 449-460.

Follett BK, King VM \& Meddle SL 1998 Rhythms and photoperiodism in birds. In Biological Rhythms and Photoperiodism in Plants, pp 231-242. Eds PJ Lumsden \& AJ Miller. Oxford: BIOS Scientific.

Freeman DA, Teubner BJ, Smith CD \& Prendergast BJ 2007 Exogenous T3 mimics long day lengths in Siberian hamsters. American Journal of Physiology. Regulatory, Integrative and Comparative Physiology 292 R2368-R2372.

Goldman BD 2001 Mammalian photoperiodic system: formal properties and neuroendocrine mechanisms of photoperiodic time measurement. Journal of Biological Rhythms 16 283-301.

Goldsmith AR \& Nicholls TJ 1992 Thyroxine effects upon reproduction, prolactin secretion and plumage molt in intact and in thyroidectomized European starlings Sturnus vulgaris. Ornis Scandinavica: Scandinavian Journal of Ornithology 23 398-404.

Hoffman RA \& Reiter RJ 1965 Pineal gland: influence on gonads of male hamsters. Science 148 1609-1610.
Hojvat S, Baker G, Kirsteins L \& Lawrence AM 1982 TSH in the rat and monkey brain. Distribution, characterization and effect of hypophysectomy. Neuroendocrinology 34 327-332.

Juss TS 1993 Neuroendocrine and neural changes associated with the photoperiodic control of reproduction. In Avian Endocrinology, pp 47-60. Ed. PJ Sharp. Bristol: Society for Endocrinology.

Kumar V Juss T \& Follett B 1993 Melatonin and the Pineal Gland: From Basic Science to Clinical Application: Proceedings of the International Symposium on Melatonin and the Pineal Gland, pp 163-168. Eds Y Touitou J Arendt \& P Pevet. Amsterdam: Excerpta Medica.

Leonard JL \& Visser TJ 1986 Biochemistry of deiodination. In Thyroid Hormone Metabolism, pp 189-229. Ed. G Hennemann. New York: Marcel Dekker.

Lincoln GA 1992 Administration of melatonin into the mediobasal hypothalamus as a continuous or intermittent signal affects the secretion of follicle stimulating hormone and prolactin in the ram. Journal of Pineal Research 12 135-144.

Lincoln GA 2002 Neuroendocrine regulation of seasonal gonadotrophin and prolactin rhythms: lessons from the Soay ram model. Reproduction Supplement 59 131-147.

Lincoln GA \& Maeda K 1992 Effects of placing micro-implants of melatonin in the mediobasal hypothalamus and preoptic area on the secretion of prolactin and $\beta$-endorphin in rams. Journal of Endocrinology 134 437-448.

Malpaux B, Daveau A, Maurice F, Gayrard V \& Thiery JC 1993 Short-day effects of melatonin on luteinizing hormone secretion in the ewe: evidence for central sites of action in the mediobasal hypothalamus. Biology of Reproduction 48 752-760.

Maywood ES, Bittman EL \& Hastings MH 1996 Lesions of the melatoninand androgen-responsive tissue of the dorsomedial nucleus of the hypothalamus block the gonadal response of male Syrian hamsters to programmed infusions of melatonin. Biology of Reproduction $\mathbf{5 4}$ 470-477.

Meddle SL \& Follett BK 1997 Photoperiodically driven changes in Fos expression within the basal tuberal hypothalamus and median eminence of Japanese quail. Journal of Neuroscience 17 8909-8918.

Moenter SM, Woodfill CJ \& Karsch FJ 1991 Role of the thyroid gland in seasonal reproduction: thyroidectomy blocks seasonal suppression of reproductive neuroendocrine activity in ewes. Endocrinology $\mathbf{1 2 8}$ 1337-1344.

Morgan PJ \& Williams LM 1996 The pars tuberalis of the pituitary: a gateway for neuroendocrine output. Reviews of Reproduction $\mathbf{1}$ 153-161.

Nakao N, Takagi T, ligo M, Tsukamoto T, Yasuo S, Masuda T, Yanagisawa T, Ebihara S \& Yoshimura T 2006 Possible involvement of organic anion transporting polypeptide $1 \mathrm{c} 1$ in the photoperiodic response of gonads in birds. Endocrinology 147 1067-1073.

Nakao N, Ono H, Yamamura T, Anraku T, Takagi T, Higashi T, Yasuo S, Katou Y, Kageyama S, Uno Y et al. 2008 Thyrotrophin in the pars tuberalis triggers photoperiodic response. Nature 452 317-322.

Nicholls TJ, Follett BK \& Robinson JE 1983 A photoperiodic response in gonadectomized Japanese quail exposed to a single long day. Journal of Endocrinology 97 121-126.

Nicholls TJ, Follett BK, Goldsmith AR \& Pearson H 1988 Possible homologies between photorefractoriness in sheep and birds: the effect of thyroidectomy on the length of the ewe's breeding season. Reproduction, Nutrition, Development 28 375-385.

Parkinson TJ \& Follett BK 1994 Effect of thyroidectomy upon seasonality in rams. Journal of Reproduction and Fertility 101 51-58.

Parkinson TJ \& Follett BK 1995 Thyroidectomy abolishes seasonal testicular cycles of Soay rams. Proceedings of the Royal Society of London, Series B: Biological Sciences 259 1-6.

Prendergast BJ, Mosinger B Jr, Kolattukudy PE \& Nelson RJ 2002 Hypothalamic gene expression in reproductively photoresponsive and photorefractory Siberian hamsters. PNAS 99 16291-16296.

Reiter RJ 1993 The melatonin rhythm: both a clock and a calendar. Experientia 49 654-664.

Revel FG, Saboureau M, Pevet P, Mikkelsen JD \& Simonneaux V 2006 Melatonin regulates type 2 deiodinase gene expression in the Syrian hamster. Endocrinology 147 4680-4687.

Saldanha CJ, Leak RK \& Silver R 1994 Detection and transduction of daylength in birds. Psychoneuroendocrinology 19 641-656. 
Schaub C, Bluet-Pajot MT, Szikla G, Lornet C \& Talairach J 1977 Distribution of growth hormone and thyroid-stimulating hormone in cerebrospinal fluid and pathological compartments in the central nervous system. Journal of the Neurological Sciences 31 123-131.

Scott CJ, Jansen HT, Kao CC, Kuehl DE \& Jackson GL 1995 Disruption of reproductive rhythms and patterns of melatonin and prolactin secretion following bilateral lesions of the suprachiasmatic nuclei in the ewe. Journal of Neuroendocrinology 7 429-443.

Sharp PJ \& Follett BK 1969 The effect of hypothalamic lesions on gonadotrophin release in Japanese quail (Coturnix coturnix japonica). Neuroendocrinology 5 205-218.

Silver R, Witkovsky P, Horvath P, Alones V, Barnstable CJ \& Lehman MN 1988 Coexpression of opsin- and VIP-like-immunoreactivity in CSF-contacting neurons of the avian brain. Cell and Tissue Research 253 189-198.

Stoeckel M \& Porte A 1984 Fine structure and development of the pars tuberalis in mammals. In Ultrastructure of Endocrine Cells and Tissues, pp 29-38. Ed. PM Motta. Boston: Martinus-Nijhoff.

Tessonneaud A, Locatelli A, Caldani M \& Viguier-Martinez MC 1995 Bilateral lesions of the suprachiasmatic nuclei alter the nocturnal melatonin secretion in sheep. Journal of Neuroendocrinology 7 145-152.

Thrun LA, Dahl GE, Evans NP \& Karsch FJ 1997 A critical period for thyroid hormone action on seasonal changes in reproductive neuroendocrine function in the ewe. Endocrinology 138 3402-3409.

Watanabe M, Yasuo S, Watanabe T, Yamamura T, Nakao N, Ebihara S \& Yoshimura T 2004 Photoperiodic regulation of type 2 deiodinase gene in Djungarian hamster: possible homologies between avian and mammalian photoperiodic regulation of reproduction. Endocrinology 145 1546-1549.

Watanabe T, Yamamura T, Watanabe M, Yasuo S, Nakao N, Dawson A, Ebihara S \& Yoshimura T 2007 Hypothalamic expression of thyroid hormone-activating and -inactivating enzyme genes in relation to photorefractoriness in birds and mammals. American Journal of Physiology. Regulatory, Integrative and Comparative Physiology 292 R568-R572.

Wilson FE \& Reinert BD 1995 A one-time injection of thyroxine programmed seasonal reproduction and postnuptial molt in chronically thyroidectomized male American tree sparrows Spizella arborea exposed to long days. Journal of Avian Biology 26 225-233.

Wittkowski W, Bergmann M, Hoffmann K \& Pera F 1988 Photoperioddependent changes in TSH-like immunoreactivity of cells in the hypophysial pars tuberalis of the Djungarian hamster, Phodopus sungorus. Cell and Tissue Research 251 183-187.
Yamamura T, Hirunagi K, Ebihara S \& Yoshimura T 2004 Seasonal morphological changes in the neuro-glial interaction between gonadotropin-releasing hormone nerve terminals and glial endfeet in Japanese quail. Endocrinology 145 4264-4267.

Yamamura T, Yasuo S, Hirunagi K, Ebihara S \& Yoshimura T $2006 T_{3}$ implantation mimics photoperiodically reduced encasement of nerve terminals by glial processes in the median eminence of Japanese quail. Cell and Tissue Research 324 175-179.

Yasuo S, Watanabe M, Okabayashi N, Ebihara S \& Yoshimura T 2003 Circadian clock genes and photoperiodism: comprehensive analysis of clock gene expression in the mediobasal hypothalamus, the suprachiamatic nucleus, and the pineal gland of Japanese quail under various light schedules. Endocrinology 144 3742-3748.

Yasuo S, Watanabe M, Nakao N, Takagi T, Follett BK, Ebihara S \& Yoshimura T 2005 The reciprocal switching of two thyroid hormoneactivating and -inactivating enzyme genes is involved in the photoperiodic gonadal response of Japanese quail. Endocrinology 146 2551-2554.

Yasuo S, Nakao N, Ohkura S, ligo M, Hagiwara S, Goto A, Ando H, Yamamura T, Watanabe M, Watanabe T et al. 2006 Long-day suppressed expression of type 2 deiodinase gene in the mediobasal hypothalamus of the Saanen goat, a short-day breeder: implication for seasonal window of thyroid hormone action on reproductive neuroendocrine axis. Endocrinology 147 432-440.

Yasuo S, Yoshimura T, Ebihara S \& Korf HW 2007a Temporal dynamics of type 2 deiodinase expression after melatonin injections in Syrian hamsters. Endocrinology 148 4385-4392.

Yasuo S, Watanabe M, ligo M, Nakamura TJ, Watanabe T, Takagi T, Ono H, Ebihara S \& Yoshimura T 2007b Differential response of type 2 deiodinase gene expression to photoperiod between photoperiodic Fischer 344 and nonphotoperiodic Wistar rats. American Journal of Physiology. Regulatory, Integrative and Comparative Physiology 292 R1315-R1319.

Yoshimura T, Yasuo S, Watanabe $M$, ligo $M$, Yamamura T, Hirunagi $K$ \& Ebihara S 2003 Light-induced hormone conversion of $T_{4}$ to $T_{3}$ regulates photoperiodic response of gonads in birds. Nature 426 178-181.

Received 28 January 2008

First decision 4 March 2008

Accepted 23 April 2008 